\title{
The future potential for wine production in Scotland under high-end climate change
}

\author{
Miriam Dunn $^{1}$ (D) Mark D. A. Rounsevell ${ }^{1,2} \cdot$ Fredrik Boberg $^{3} \cdot$ Elizabeth Clarke $^{1}$. \\ Jens Christensen $^{3,4}$ - Marianne S. Madsen ${ }^{3}$
}

Received: 25 April 2017 / Accepted: 21 October 2017 /Published online: 25 November 2017

(C) The Author(s) 2017. This article is an open access publication

\begin{abstract}
Wine production is climate dependent and highly sensitive to weather variability, which makes the sector a good indicator of ongoing and future climate change impacts. Under high-end climate change (HECC), temperatures in Scotland are projected to increase significantly by the end of the twenty-first century. This raises the possibility of future temperatures becoming sufficiently high to support the growth of wine grapes. In this paper, we explore to what extent Scotland might become suitable for wine production under
\end{abstract}

Editor:Tony Weir.

Electronic supplementary material The online version of this article (https://doi.org/10.1007/s10113-017-1240-3) contains supplementary material, which is available to authorized users.

Miriam Dunn

miriam.dunn@ed.ac.uk

Mark D. A. Rounsevell

mark.rounsevell@ed.ac.uk

Fredrik Boberg

fbo@dmi.dk

Elizabeth Clarke

elizabeth.clarke@ed.ac.uk

Jens Christensen

hesselbjerg@nbi.ku.dk

Marianne S. Madsen

msm@dmi.dk

1 Institute of Geography, School of Geosciences, University of Edinburgh, Drummond street, Edinburgh EH8 9XP, UK

2 IMK-IFU, Karlsruhe Institute of Technology, Karlsruhe, Germany

3 Danish Meteorological Institute, Copenhagen, Denmark

4 Niels Bohr Institute, University of Copenhagen, Copenhagen, Denmark
HECC using a climate analogue approach. Specifically, we address the following questions. What are the projected late twenty-first century temperature changes in Scotland? Where in Europe are current climates (based on summer and annual temperatures) similar to those projected for Scotland by the end of the twenty-first century under HECC? Are any of these locations currently wine grape growing regions? The temperature analogues towards the end of the twenty-first century occurred at more southerly latitudes in Europe, with some variability from west to east arising from the influence of continental climates. Temperature analogues alone match with several current wine grape growing regions of Europe, suggesting that future climates in Scotland could support wine production. However, when precipitation and/or lithology and topography are also taken into account, no matches were found with existing European wine grape growing regions. This study demonstrates how the use of climate analogues in combination with other environmental datasets can be useful in understanding future climate change impacts, especially under HECC.

Keywords High-end climate change $\cdot$ Scotland . Climate analogues $\cdot$ Wine grapes $\cdot$ Wine production

\section{Introduction}

Under high-end climate change (HECC), temperatures in Scotland are projected to increase significantly by the end of the twenty-first century (e.g. Christensen et al. 2013). However, the potential sectoral implications of these changes based on a likely future climate in Scotland are more useful and relevant to adaptation decision-making than focusing solely on the changes in climatic variables. A potential implication for land use in Scotland under HECC would arise from 
changes in growing season temperatures and the associated possibility of producing different agricultural and horticultural crops; including, for example, wine grapes.

Grape vines are cultivated in a natural environment-referred to as the 'terroir' (Gladstones 1992). The 'terroir' influences the quality and quantity of grapes produced, and the particular characteristics of the grapes produced at a particular site (Gladstones 1992). There are a variety of influences on the terroir in different viticultural regions (Gladstones, 2004). However, there are three main components of terroir-soil, climate and cultivar. Of these three, climate has the largest influence on terroir (Leeuwen et al. 2004), and hence on the suitability of a region for growing particular grape varieties (Gladstones, 2004; Jones et al. 2005; Webb et al. 2011; Jones et al. 2012). This is because grape vines are sensitive to climatic conditions and variations in the weather; so different grape varieties are best suited to particular conditions of temperature and precipitation (Gladstones 1992, 2004).

Climatic conditions strongly affect the quality and quantity of grapes produced, and hence also the quality of each year's wine (Gladstones 2004; Webb et al. 2008). Current wine producing regions face the necessity of adapting to climate change because of the dependency of grape varieties on particular climatic conditions and the long-lived nature of vines (Diffenbaugh et al. 2011; Metzger and Rounsevell, 2011; Webb et al. 2010). One way of adapting to climate change would be the poleward movement of viticultural regions.

Wine grapes are grown extensively across central and western Europe (Fig. 1), but other than in southern England, are not grown on a commercially viable basis in the UK or at other northerly latitudes. This is due primarily to growing season temperatures being lower than required at higher latitudes. Under HECC, however, growing season temperatures are projected to increase and so, areas at higher latitudes might become suitable for wine grape production in the future.

Research on climate change and viticulture has focused primarily on impacts to existing wine grape growing regions (e.g. Battaglini et al. 2009, de Orduña 2010, Jones et al. 2005). This includes, for example, temperature changes observed recently in specific wine regions (e.g. Jones et al. 2005), how these changes have affected and are affecting the phenological stages of vines (de Orduña 2010, Jones and Davis 2000, Ramos et al. 2015, Schultze et al. 2016b, Webb et al. 2007, 2011, 2012), which current wine producing areas may become unsuitable in the future (Jones et al. 2010, Tóth and Végvári 2016), which varieties may be suitable in changing climate conditions (Schultze et al. 2016a), how climate change influences incremental and transformative change in the wine grape sector (e.g. Battaglini et al. 2009, Park et al. 2012, Schultze et al. 2016b) and the problems faced by existing wine producing areas in adapting to climate change (Metzger and Rounsevell, 2011), including late frost risk (Molitor et al. 2014). Existing research on the potential poleward expansion of suitable viticulture areas in response to high-end climate change is limited, but shows that this trend is both projected and already occurring in the USA (e.g. Jones et al. 2010, Schultze et al. 2016a, 2016b) and elsewhere in the world (e.g. Jones et al. 2005). For example, Schultze et al. (2016a, 2016b) used downscaled CMIP5 projections showed that the climate of western Michigan state moved from unsuitable to suitable for wine production over approximately 40 years, due to climate change.

Climates throughout the world's wine-producing regions have changed over the past 50 years (Jones et al. 2005, Webb et al. 2011). And research has shown that it is likely that many current wine grape producing regions will decline in the coming decades, largely due to warmer growing seasons pushing grape varieties beyond their optimum growing conditions (de Orduña 2010, Jones et al. 2005, Webb et al. 2011). There is only so much that adaptation in the wine sector can achieve (e.g. Diffenbaugh et al. 2011, Hall and Jones, 2009, Lereboullet et al. 2013, Metzger and Rounsevell, 2011). Long-term strategic planning is inherent in the viticulture industry, including decisions on buying or selling vineyards. Future climate information, where available, can assist these investment decisions.

The method of climate analogues has been used previously to study the implications of a future climate for a region (e.g. Hallegate et al. 2007). Analogues provide an indication of what the future climate of a given location could be like in comparison to the current climate of another location (Grenier et al. 2013, Ramirez-Villegas et al. 2011), with the comparison based on climatic variable(s). Climate analogue information has been produced for some wine regions of the world (e.g. Jones et al. 2009, 2010, Smart 2003, White et al. 2006, Webb et al. 2007, Webb et al. 2013), but this is not comprehensive. The most comprehensive work covers 23 regions worldwide, ranging from cool- to hot-classified, and provides a typological representation of the breadth of the expected climatic change (Webb et al. 2013). However, this work focuses on current wine producing regions, rather than including potential additional future wine producing regions, such as Scotland.

Wine grape growers currently use climate analogue data in climate change adaptation planning (e.g. Dunn et al. 2015). Analogues can be used to better understand the challenges and opportunities growers may face in the future by comparing existing crop choices, horticultural techniques and procedures with those employed currently to manage vineyards in climate analogue locations. This leads to better understanding and decision-making for climate change adaptation by learning about how these problems (for example, increased incidence of disease due to higher temperatures and excessive moisture) are currently overcome elsewhere.

This paper explores the potential for wine grape production in Scotland under HECC by the end of the twenty-first century using a climate analogue approach. The study addresses the 


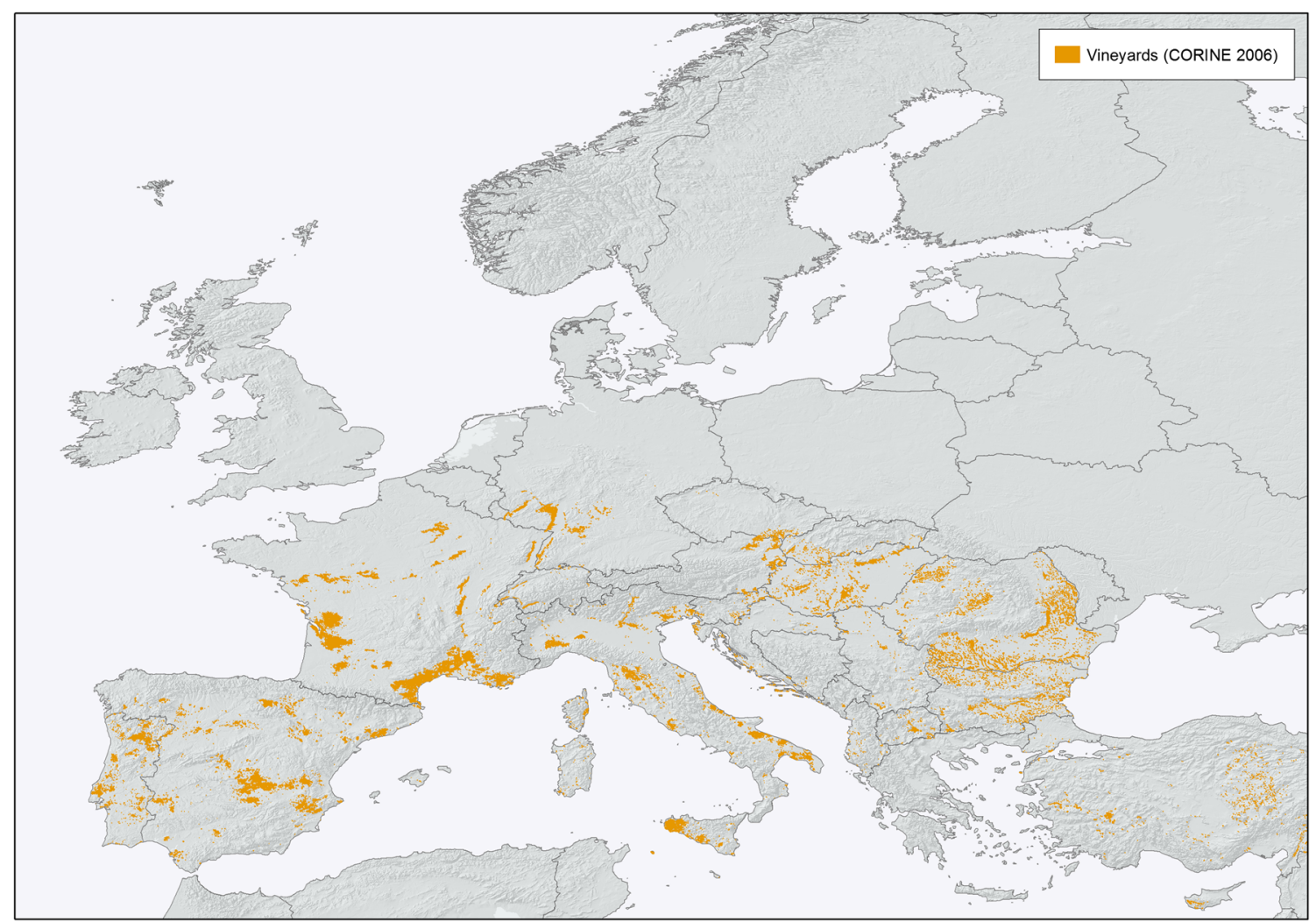

Fig. 1 Location of wine grape growing regions across Europe (map data sourced from CORINE Land Cover 2006 (EEA 2014))

following questions. What are the projected late twenty-first century temperature changes in Scotland? Where in Europe are current climates (based on summer and annual temperatures) similar to those projected for Scotland by the end of the twenty-first century under HECC? Are any of these locations currently wine grape growing regions? The focus of this study is on providing a picture of what a HECC future might look like from 'potential futures' that already occur elsewhere. This insight supports adaptation to HECC through management changes that anticipate these potential futures.

\section{Method}

Seven locations in Scotland were selected with different climates and diverse landscapes, but some potential for wine grape production under a changed climate (according to existing research that shows poleward expansion of viticultural regions into northern UK latitudes, e.g. Fraga et al. 2013). These included coastal, inland and mountain hill-slope locations. The locations were as follows: (i) the island of Hoy (in the Orkneys), (ii) Loch Ness, (iii) Glen Coe, (iv) Innerleithen, (v) Quiraing (the Trotternish Ridge on Skye), (vi) the Fife coastal path and (vii) Loch Etchachan (in the Cairngorms National Park).

Future climate analogues, for summer (JJA) and annual temperature and precipitation were derived for these locations from the EC-Earth Earth System model (Hazeleger et al.
2012) for HECC, downscaled to a grid size of $12 \times 12 \mathrm{~km}$ using the HIRHAM model (Christensen et al. 2006; LucasPicher et al. 2013). Comparison of climatic variables within a defined tolerance of HECC (RCP 8.5) using model outputs for the periods 2011-2040, 2041-2070 and 2071-2100 indicated locations within Europe that currently have the summer and annual climate (temperature and precipitation) characteristics that could be analogous to the climate of Scotland under HECC at the end of the twenty-first century.

Different soil types can affect, among other aspects, the ripening of grapes and their levels of acidity (Gladstones 2004). Topography also affects the meso-climate of the location, influencing, for example, frost occurrence due to cold air drainage (Gladstones 2004). Since soil characteristics and topography are key factors that influence successful viticulture (Gladstones 2004), a further screening of the climate analogues was undertaken from similarity in lithology (soil type and parent material) and topography (elevation). Lithology data were derived from GLiM, the new global lithological map database (Hartmann and Moosdorf 2012). Topography/ landform data were sourced from a European Environment Agency dataset (EEA 2014). Thus, a subset of the climate analogues was identified in which the lithology and topography also matched the locations in Scotland. Further details of the method are provided in Online Resource 1.

The results of this analysis are presented in the following order. Future climate analogue locations are presented based 
only on average annual temperatures. This is followed by exploration of differences in climate analogue locations if summer (rather than annual) temperatures are used in the analysis. Then the lithology and topography are introduced to explore whether or not these affect the number and location of the analogues. Finally, the impact of precipitation is tested on the number and location of analogues with reference to current precipitation regimes in wine producing regions.

\section{Results}

\section{Projected late twenty-first century temperature changes in Scotland}

Projected annual temperature changes for Scotland over three time periods in the early, middle and late twenty-first century under RCP8.5 are shown in Table 1. These projections indicate that, under HECC, Scotland is projected to experience average temperature increases of about $+3{ }^{\circ} \mathrm{C}$, increasing in the latter part of the century, and varying seasonally. The temperate, maritime Scottish climate is, however, relatively warm compared with other parts of Europe at a similar latitude. The late twenty-first century higher annual temperatures projected for Scotland arise from relatively milder winters, rather than significantly hotter summers, i.e. there is a small amplitude in annual temperature. Maps indicating the seasonal relative temperature changes for Scotland under RCP 8.5 are provided in Online Resource 1.

Current temperature analogues for Scotland's projected future temperatures later in the twenty-first century

An example of mapped analogue locations for annual temperature is given, as a representative example, for the Isle of Hoy (Fig. 2; located at approximately $60^{\circ} 11^{\prime} 8^{\prime \prime} \mathrm{N},-1^{\circ} 19^{\prime} 21^{\prime \prime} \mathrm{W}$ ).

Table 1 RCP8.5 temperature projections for 39 CMIP5 models relative to 1981-2010. The table shows the 25th, 50th and 75th percentiles of the projected regional changes in mean annual and summer temperature for Scotland and (in parentheses) Northern Europe. A full list of CMIP models considered for this analysis is provided in Online Resource 2

\begin{tabular}{llllll}
\hline \multirow{2}{*}{ Time period } & Season & \multicolumn{4}{l}{ Temperature change $\left({ }^{\circ} \mathrm{C}\right)$} \\
\cline { 3 - 6 } & & 25th & 50 th & 75th \\
\hline RCP8.5 & \multirow{2}{*}{$2011-2040$} & ANN & $0.5(1.0)$ & $0.7(1.3)$ & $1.0(1.7)$ \\
& & JJA & $0.4(0.8)$ & $0.7(1.1)$ & $1.1(1.5)$ \\
& \multirow{2}{*}{$2041-2070$} & ANN & $1.4(2.4)$ & $1.6(3.0)$ & $2.1(3.5)$ \\
& JJA & $1.6(2.0)$ & $1.8(2.5)$ & $2.3(3.1)$ \\
& \multirow{2}{*}{$2071-2100$} & ANN & $2.2(4.0)$ & $2.8(4.7)$ & $3.4(5.7)$ \\
& JJA & $2.3(3.3)$ & $3.0(4.2)$ & $3.5(5.3)$ \\
\hline
\end{tabular}

The red crosses in Fig. 2 represent future climate analogues for the island of Hoy, under the RCP8.5 scenario during the period 2071-2100. In other words, the red crosses represent the locations where the current climate matches that which is projected for Hoy in the future period of 2071-2100. These are based on (i) annual mean temperatures within $\pm 0.25^{\circ} \mathrm{C}$ of the historical period 1981-2010 for the current locations; and (ii) a model elevation within $200 \mathrm{~m}$ of the grid point representing Hoy. Temperature analogues under HECC in the latter part of the twenty-first century include locations in: Austria, Belgium, Bulgaria, Croatia, the Czech Republic, England, France, Germany, Hungary, Ireland, Italy, Moldova, the Netherlands, Romania, Slovakia and Wales. Some of these locations match current wine producing regions (a full list of which is provided in Online Resource 3).

Projected summer temperatures indicate somewhat different analogues than for the annual temperatures. Summer temperature analogues occur more northerly in Europe in locations that are currently without commercially viable wine grape production (with the exception of southern England; Fig. 3). The annual average temperature analogues mask the inter-seasonal variability, which for Scotland is relatively small compared with more continental-influenced climates in other parts of Europe. This suggests that future Scottish summers are likely to remain too cool for commercially viable wine grape production. A larger number of analogue locations were found for projected annual temperature because this variable averages out important seasonal differences. However, for wine producing suitability summer temperatures are more important because (i) the hottest temperatures occur in this season, (ii) wine grapes ripen during the summer months, so temperatures during this season are particularly important and (iii) annual data can smooth out the seasonal differences that are important to growing season success.

Figures showing the location of the (summer and annual) temperature analogues in all three time periods, for RCP8.5 are presented in Online Resource 4.

\section{Lithology and topography}

An example of the results of the process of matching lithology and topography is shown for each of the three time periods for the Isle of Hoy (Fig. 4). This figure demonstrates that the inclusion of these extra variables dramatically decreases the number of matched locations; and that the remaining matches are no longer in current wine-producing areas.

Maps presenting this subset of analogue locations (based on temperature, lithology and topography) for each of the time periods for each selected Scottish location are presented in Online Resource 5. The mapping of temperature analogues on the basis of lithology and topography across the three time periods (early, middle and late century) also demonstrates a general tendency for analogue locations to shift towards more 


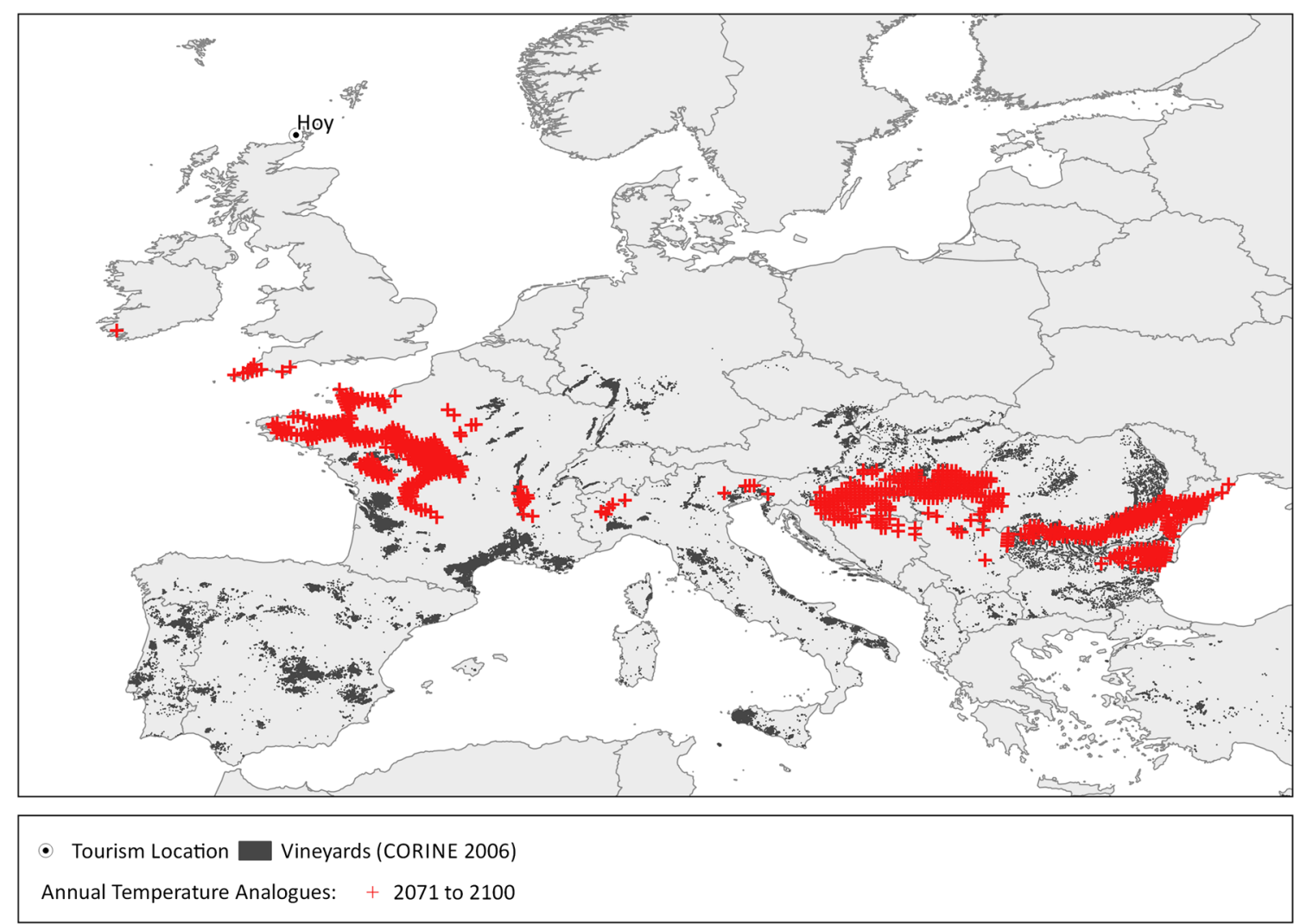

Fig. 2 Annual temperature analogues (red crosses) for the island of Hoy, in the north of Scotland, projected under RCP8.5 in the time period 2071-2100

southerly latitudes later in the twenty-first century with the projected temperature increase.

\section{Precipitation}

Precipitation projections, within Scotland, are more variable (Table 2), which is in part a reflection of the greater interannual variability under current climate conditions. Seasonal precipitation changes show different directional changes (wetter and drier) as well as differences in the magnitude of change (Online Resource 6), both between seasons and between time periods. In general, summer (JJA) is projected to be drier, particularly towards the latter parts of the twenty-first century; while winter is projected to be wetter. Overall, changes in precipitation are projected to be relatively small. Maps indicating the seasonal relative precipitation changes for Scotland under RCP 8.5 are provided in Online Resource 6.

Due to variability in the direction and magnitude of projected changes in precipitation both seasonally and temporally, no analogues were found that matched both projected temperature change and precipitation change. This underlines some of the limitations in defining climate analogues intrinsic to the method and should also be kept in mind when applied to more processed climate indexes (e.g. Hugglin- or Winklerindex; Hugglin 1986, Amerine and Winkler 1944), giving analogues based on basic climatic variables first priority.
However, to explore whether or not precipitation might be limiting to future wine production in Scotland, a comparison was made between the projected precipitation for Scotland and current precipitation in some of the analogue locations. The tabulated results of this analysis are shown in Online Resource 7. Examples are presented for two Scottish locations and example analogue locations from relatively wet wine production regions. Results show that projected decreases in summer precipitation in Scotland bring the Scottish locations closer to the average summer precipitation currently experienced in these example analogue locations. However, the annual rainfall projections for the Scottish locations are significantly higher than the current precipitation in the analogue locations; in some instances, by more than three times. Higher annual rainfall, in Scotland, is typically attributable to precipitation falling in the autumn and winter months (not shown).

\section{Summary of results}

As shown in sections 3.1 to 3.3 , the analogue locations only match some current (cool climate) wine producing regions when projected annual temperature changes alone are considered. If summer temperatures are included then wine production becomes marginal. But the addition of lithology, topography and precipitation largely excludes the potential for wine 


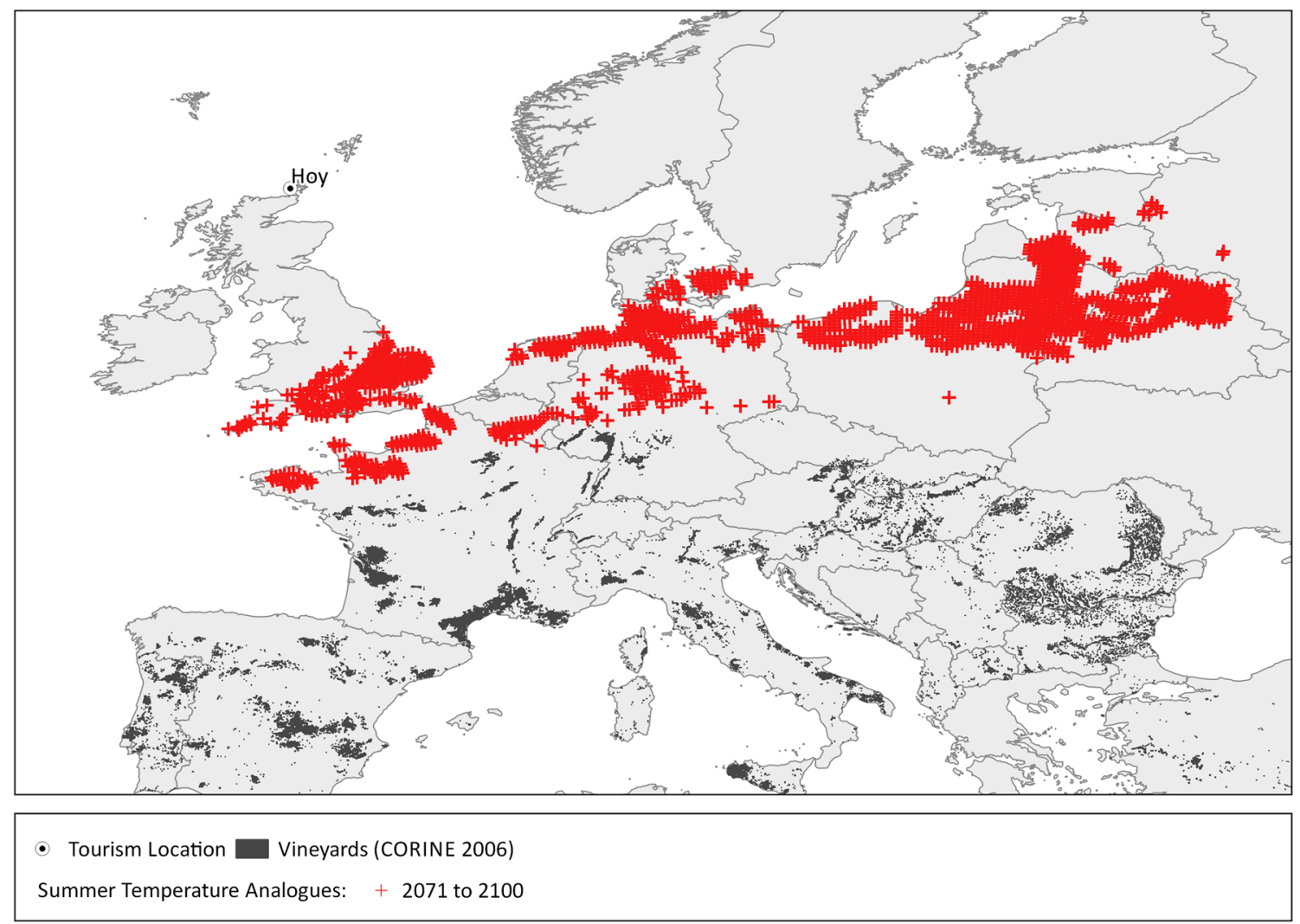

Fig. 3 Summer temperature analogues (red crosses) for the island of Hoy, in the north of Scotland, under RCP8.5 in the time period 2071-2100. Note that these locations are more northerly in latitude, on average, than for the annual temperature analogues

production in Scotland even under HECC at the end of the twenty-first century (see Fig. 4).

If we consider analogue locations based on annual temperature alone, then six of the example Scottish locations have projected annual temperature analogue locations in current wine producing regions (see Online Resource 3). Maps showing these temperature analogues are presented in Online Resource 4 and Online Resource 5.

\section{Discussion}

The Scottish climate analogues for the future climate projections typically occur at more southerly latitudes in the latter twenty-first century. Exceptions are a consequence of the influence of continental climates (the distance of a location from the coast), and the specific influence of the North Atlantic Ocean, which makes the UK climate more moderate than in Scandinavia at similar latitudes. This continental influence explains the unexpected location of a small subset of the climate analogues identified in more northerly latitudes; summer climates in these locations are currently warmer than in Scotland.

The finding that analogues only match some existing wine regions if annual (rather than summer) temperature is considered suggests that wine grape production in Scotland under
HECC, at the end of the century, remains implausible on a commercial scale. This is in part explained by the projected summer temperatures remaining relatively cool and similar to current summer temperatures in northerly latitudes that do not produce wine grapes. Analysis of the annual temperature averages out these important seasonal differences and therefore does not reflect the current strongly seasonally divergent (very warm/very cold) climate experienced in many of the climate analogue locations. The climate analogues that were further filtered according to lithology and topography showed even fewer matches and excluded many of those locations in current wine grape producing regions.

It is also possible that the results are being influenced by the limitations of the 2006 CORINE dataset. While there are no matches based on this dataset, it is possible that there may be matches using a more up to date and/or higher resolution dataset. The authors are aware that there is wine being produced in the more northern areas, for example in Denmark, Schleswig-Holstein (Germany), Lower Saxony (Germany) and other regions where it is not shown on the 2006 dataset, but where some of the climate analogues appear. Although these are small production areas, they have grown substantially in both size and number over the past decade. There is also circumstantial evidence of wine being produced in more poleward regions during the Medieval Warm Period (Pfister 


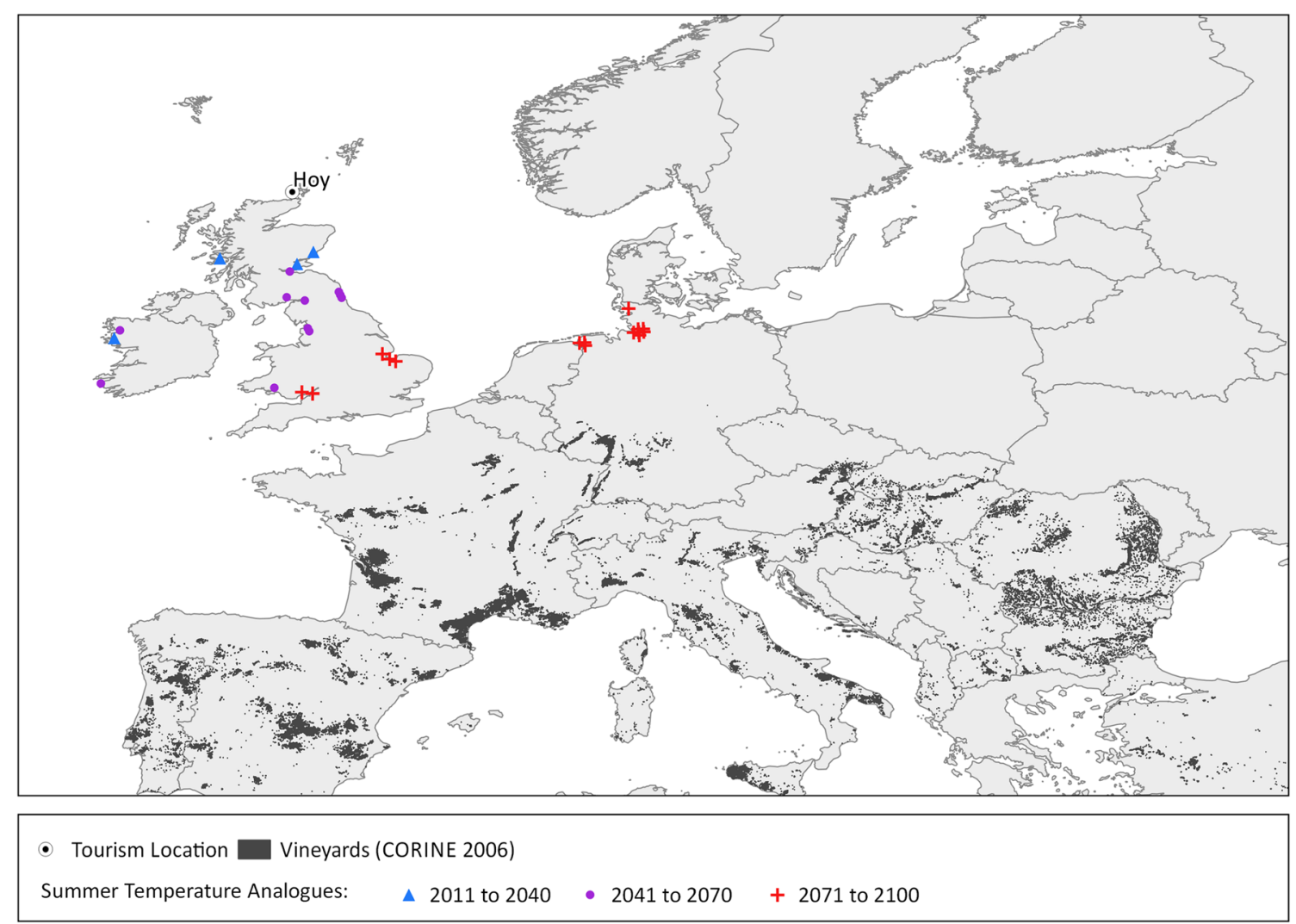

Fig. 4 Summer temperature analogues for the island of Hoy (Orkneys), under RCP 8.5 for the timeslices 2011-2040 (triangles), $2041-2070$ (circles), and 2071-2100 (crosses), showing only those locations that are matched with the original location's lithology and topography

1988), including along the Baltic Coast. Given that global temperatures are rising beyond the conditions in that period, it remains plausible that production may return to those regions (if it has not already done so). This hypothesis that wine is being produced in areas not picked up by the CORINE dataset is also supported by the newly reinforced warming trend in global temperatures, with 2016 global surface temperature now being highest on record. In fact, record warmth

Table 2 RCP 8.5 precipitation projections for 39 CMIP5 models relative to 1981-2010. The table shows the 25th, 50th and 75 th percentiles of the projected regional relative changes in mean annual and summer precipitation for Scotland and (in parentheses) Northern Europe

\begin{tabular}{llllll}
\hline \multirow{2}{*}{ Time period } & Season & \multicolumn{3}{l}{ Precipitation change $(\%)$} \\
\cline { 3 - 5 } & & & 25 th & 50 th & 75 th \\
\hline \multirow{2}{*}{ RCP8.5 } & \multirow{2}{*}{$2011-2040$} & ANN & $1(3)$ & $2(4)$ & $4(6)$ \\
& & JJA & $-3(-1)$ & $-1(4)$ & $3(6)$ \\
& \multirow{2}{*}{$2041-2070$} & ANN & $2(7)$ & $4(9)$ & $6(12)$ \\
& JJA & $-8(-2)$ & $-4(3)$ & $2(10)$ \\
& & & & & \\
& $2071-2100$ & ANN & $5(10)$ & $8(14)$ & $11(19)$ \\
& JJA & $-14(-4)$ & $-8(3)$ & $-2(12)$ \\
\hline
\end{tabular}

has been recorded for a third consecutive year, with the 2016 annual global surface temperature surpassing the previous record of 2015 (Blunden and Arndt 2017).

The novelty of this approach is that existing studies that use climate analogues to explore the suitability of particular climates for wine grape production (e.g. Smart 2003, Tóth and Végvári 2016) do not explore the effects of high-end climate change in areas where wine is not currently produced. The analogue approach is a way of exploring adaptation strategies for potential futures that is applicable to other regions, crops (production sectors) or study themes. The analogues can also provide a clearer insight into what that future might look like, beyond what climate projections can do alone. For example, if the temperature is projected to increase by 3 degrees, what does that mean in practice? The analogue approach can provide the answer to this question.

The climate analogue approach we have taken here is quite simple and more advanced methods using multi-variate approaches may lead to somewhat refined results. But we note that (i) in all of our examples it is impossible to find 'exact' analogues (accurately for all variables, leaving additional analysis to sort out where most of the match comes from and assessing the sensitivity to choices made on how well the analogue should match); (ii) here, analogues are based only on a limited set of variables to define them and ignores others, e.g. 
windiness/storminess would impact vines in Scotland; (iii) as applied here, the approach ignores full seasonality, climate variability and focuses on means; (iv) a north-south shift does not include the radiative differences from a higher or lower position of the sun in the sky; (v) other factors, such as daylength also affect the ripening of wine grapes, because at high latitudes day-length affects the amount of solar radiation received by the plant and (vi) the climate analogue approach ignores local human effects, including for example management approach (e.g. using micro climatological information) and choice of grape varieties. The latter three points are particularly pertinent, as the good years in wine production can often compensate for the bad years. For example, it is possible for a manager to choose not to pick (or produce wine from) grapes from a year with low quality fruit caused by unfavourable climatic conditions (e.g. low temperatures, cloudiness, high rain during flowering and/or close to harvest). But, 1 year without production does not necessarily mean that the business is no longer viable; as non-production limits supply and can increase prices for other vintages. Addressing these caveats could provide future avenues for research.

It is also important to remember that this work uses time slices that each average across three decades, which results in warming that is less pronounced than may be expected over shorter time periods, especially in the latter part of the century. Therefore, it is also possible that an average temperature increase of 3 degrees $C$ over this 2071-2100 time period could mean much warmer temperatures especially towards the end of that period.

The results presented here rely on only one regional model downscaling one GCM. This limits the study in the sense that the results do not reflect the potential differences arising a wider suite of models. However, taking the approach of only looking at the climate anomalies suggests that the analogues identified are not widely different from what would have resulted from using different model combinations or even from all available models. The overall conclusion that the uncertainty in precipitation projections and in particular the likely event of Scottish climate remaining moist and possibly even wetter under HECC suggests that the results of the present study are robust. The largest uncertainty within the present analysis relates to the timing of the achievement of the 3 degrees $\mathrm{C}$ increase; using a different global model — regional model combination could possibly result in an average 3 degrees $\mathrm{C}$ warming being reached either earlier or later than 2071-2100. However, in this study, the timing is not the most important element of the analysis.

Further to this, we note that the resolution of the RCM itself represents a limitation. Simply put, a higher resolution RCM may have yielded different results as representing data at a finer resolution would allow for the climate model to better resolve local microclimates. Many of the areas in the world that have recently gained the ability to accommodate wine grapes take advantage of microclimates that arise from topographic influences (aspect, slope) and a number of other landatmospheric interactions. For example, a grower in a borderline 'too cool' climate would want to grow grapes on a southwest facing slope of at least $5-15 \%$ in order to drain out cold air and to get direct insolation (for maximum photosynthesis) in the afternoon. If the same grower planted on a north facing slope or flat ground in the same climate, wine grape production would be completely untenable. Although picking up those influences may not be achieved even by using a very highresolution (e.g. using a few kilometres grid point spacing) RCM, a model at such resolution may be able to pick up more on the microclimate influences and thus given more potential options for where grapes could be grown in Scotland.

Rainfall was not used in the analogue matching since (i) the seasonal differences in direction and magnitude of change mean that the precipitation data are highly variable and therefore more uncertain than temperature, and (ii) because of this there were no analogue locations when precipitation was included. However, basic analysis of current monthly and projected future precipitation indicates that projected decreases in summer precipitation do not suggest water limitations on wine grape production; rather, these decreases bring the Scottish locations closer to the summer precipitation experienced in some of their (annual) analogue locations. Hence, decreases in summer precipitation are not limiting to potential viticulture in Scotland. In fact, drier conditions later in the season help with grape maturing and help to reduce the incidence of pests and diseases affecting the vines (Gladstones 1992). However, the annual rainfall projections for the Scottish locations are significantly higher than the current precipitation in the analogue locations; in some instances, by more than three times the current precipitation. Hence, too much precipitation would more likely be a limiting factor in the Scottish locations because of the prevalence of fungal diseases under wet conditions and physical damage to grapes under intense rainfall. Where the majority of the precipitation falls in the autumn and winter months, as is typical in Scotland, commercial viticulture may still be possible under favourable soil and drainage conditions.

In exploring climate analogues, it is important to note that the results presented are not predictions, only examples of what the Scottish climate might become like under HECC and the potential implications of those changes.

\section{Conclusions}

No climate analogues were found that were good matches for both projected temperature and precipitation in Scotland by the late twenty-first century. Analogue locations were found that match projected annual and summer temperatures 
reasonably well. These analogues are further south in latitude in almost all examples. However, the temperature analogues only match some existing wine regions if annual, but not summer, temperature is considered, and if lithology and topography are ignored. This lack of matching was partially due to the relatively small overall temperature changes, under HECC, for Scotland (annual average of $+3{ }^{\circ} \mathrm{C}$ ), but specifically to the small changes in future summer temperatures (average of $+3{ }^{\circ} \mathrm{C}$ ) that are critical to grape ripening. Moreover, projected precipitation for the Scottish locations is much higher than for the climate analogues in wine producing areas, suggesting that precipitation would also be limiting. Hence, these findings suggest that wine grape production in Scotland under HECC at the end of the twenty-first century remains implausible on a commercial scale. However, it is possible that the results are being influenced by the date and spatial resolution of the 2006 CORINE dataset. While there are no matches based on this dataset, it is possible that there may be matches using a more up to date and/or higher resolution dataset.

While the results imply that the introduction of commercial wine grape production in Scotland during the next century is unlikely, they have also shown that climate analogues are a valuable tool for visualising different possible futures and exploring potential adaptation options. For example, climate analogues can be used more broadly to guide sectoral adaptation to climate change. These climate analogues can be contextualised to provide practical, usable information about how people in different land use sectors manage within the context of their climate; lessons that could help to guide those sectors in Scotland with both incremental and transformative adaptation to HECC.

Acknowledgements The authors also acknowledge the World Climate Research Programme's Working Group on Coupled Modelling, which is responsible for CMIP, and we thank the climate modelling groups (Table S1) for producing and making available their model output. For CMIP the U.S. Department of Energy's Program for Climate Model Diagnosis and Intercomparison provides coordinating support and led development of software infrastructure in partnership with the Global Organization for Earth System Science Portals.

Funding information The research leading to these results has received funding from the European Community's Seventh Framework Programme (FP7/2007-2013) under grant agreement no 603416, IMPRESSIONS Project (IMPRESSIONS-Impacts and Risks from High-End Scenarios: Strategies for Innovative Solutions (www. impressions-project.eu)).

Open Access This article is distributed under the terms of the Creative Commons Attribution 4.0 International License (http:// creativecommons.org/licenses/by/4.0/), which permits unrestricted use, distribution, and reproduction in any medium, provided you give appropriate credit to the original author(s) and the source, provide a link to the Creative Commons license, and indicate if changes were made.

\section{References}

Amerine MA, Winkler AJ (1944) Composition and quality of musts and wines of California grapes. Hilgardia 15:493-675. https://doi.org/ 10.3733/hilg.v15n06p493

Blunden J, Arndt DS (2017) State of the climate in 2016. Bull Am Meteorol Soc 98(8):Si-S277. https://doi.org/10.1175/ 2017BAMSStateoftheClimate.1

Battaglini A, Barbeau G, Bindi M, Badeck F-W (2009) European winegrowers' perceptions of climate change impact and options for adaptation. Reg Environ Chang 9(2):61-73. https://doi.org/10. 1007/s10113-008-0053-9

Christensen JH, Krishna Kumar K, Aldrian E, An S-I, Cavalcanti IFA, de Castro M, Dong W, Goswami P, Hall A, Kanyanga JK, Kitoh A, Kossin J, Lau N-C, Renwick J, Stephenson D, Xie S-P, Zhou T (2013) Climate phenomena and their relevance for future regional climate change. In: Stocker TF, Qin D, Plattner G-K, Tignor M, Allen SK, Boschung J, Nauels A, Xia Y, Bex V, Midgley PM (eds) Climate change 2013: the physical science basis. Contribution of Working gRoup I to the Fifth Assessment Report of the Intergovernmental Panel on Climate Change. Cambridge University Press, Cambridge and New York, pp 1217-1308. https://doi.org/10.1017/CBO9781107415324.028

Christensen OB, Drews M, Christensen JH, Dethloff K, Ketelsen K, Hebestadt I, Rinke A (2006) The HIRHAM regional climate model. Version 5. DMI Technical Report No. 06-17, ISSN: 1399-1388

de Orduña RM (2010) Climate change associated effects on grape and wine quality and production. Clim Chang Food Sci 43(7):1844 1855. https://doi.org/10.1016/j.foodres.2010.05.001

Diffenbaugh NS, White MA, Jones GV, Ashfaq M (2011) Climate adaptation wedges: a case study of premium wine in the western United States. Environ Res Lett 6:1-10

Dunn MR, Lindesay JA, Howden M (2015) Spatial and temporal scales of future climate information for climate change adaptation in viticulture: a case study of user needs in the Australian winegrape sector. Aust J Grape Wine Res 21(2):226-239. https://doi.org/10.1111/ ajgw. 12138

EEA (2014) CORINE land cover 2006 (version 17), European Environment Agency. Available online at: http://www.eea.europa. eu/data-and-maps/data/elevation-breakdown

Fraga H, Malheiro AC, Moutinho-Pereira J, Santos JA (2013) Future scenarios for viticultural zoning in Europe: ensemble projections and uncertainties. Int J Biometeorol 57(6):909-925. https://doi.org/ 10.1007/s00484-012-0617-8

Gladstones J (1992) Viticulture and environment. Winetitles, Underdale

Gladstones JS (2004) Climate and Australian viticulture. In: dry PR, Coombe BG (eds) viticulture. Volume 1 - resources, 2nd edn. Winetitles Pty Ltd, Adelaide, pp 90-118. ISBN: 0975685007

Grenier P, Parent A-C, Huard D, Anctil F, Chaumont D (2013) An assessment of six dissimilarity metrics for climate analogs. J Appl Meteorol Climatol 52:733-752. https://doi.org/10.1175/JAMC-D12-0170.1

Hall A, Jones GV (2009) Effect of potential atmospheric warming on temperature-based indices describing Australian winegrape growing conditions. Aust J Grape Wine Res 15:97-119. https://doi.org/10. 1111/j.1755-0238.2008.00035.x

Hallegatte S, Hourcade J-C, Ambrosi P (2007) Using climate analogues for assessing climate change economic impacts in urban areas. Clim Chang 82:47-60. https://doi.org/10.1007/s10584-006-9161-z

Hartmann J, Moosdorf N (2012) The new global lithological map database GLiM: a representation of rock properties at the earth surface. Geochem Geophys Geosyst 13(12). https://doi.org/10.1029/ 2012GC004370

Hazeleger W, Wang X, Severijns C, Ștefănescu S, Bintanja R, Sterl A, Wyser K, Semmler T, Yang S, van den Hurk B, van Noije T, van der 
Linden E, van der Wiel K (2012) EC-earth V2.2: description and validation of a new seamless earth system prediction model. Clim Dyn 39:2611. https://doi.org/10.1007/s00382-011-1228-5

Huglin P (1986) Biologie et écologie de la vigne. Lavoisier (Edition Tec \& Doc), Paris 1986, ISBN 2-60103-019-4. S. 292 (371 S)

Jones GV, Davis RE (2000) Climate influences on grapevine phenology, grape composition, and wine production and quality for Bordeaux, France. Am J Enol Vitic 51(3):249-261

Jones GV, White MA, Cooper OR, Storchmann K (2005) Climate change and global wine quality. Clim Chang 73:319-343. https://doi.org/ 10.1007/s10584-005-4704-2

Jones G, Moriondo M, Bois B, Hall A, Duff A (2009) Analysis of the spatial climate structure in viticulture regions worldwide. Bull l'OIV 82:507-518

Jones GV, Duff AA, Hall A, Myers JW (2010) Spatial analysis of climate in winegrape growing regions in the western United States. Am J Enol Vitic 61:313-326

Jones GV, Reid R, Vilks A (2012) Climate, grapes, and wine: structure and suitability in a variable and changing climate. In The Geography of Wine (pp. 109-133). Springer Netherlands.

Lereboullet A-L, Beltrando G, Bardsley DK (2013) Socio-ecological adaptation to climate change: a comparative case study from the Mediterranean wine industry in France and Australia. Agric Ecosyst Environ 164:273-285. https://doi.org/10.1016/j.agee.2012. 10.008

Lucas-Picher P, Boberg F, Christensen JH, Berg P (2013) Dynamical downscaling with reinitializations: a method to generate fine-scale climate data sets suitable for impact studies. J Hydrometeorol 14: 1159-1174. https://doi.org/10.1175/JHM-D-12-063.1

Metzger MJ, Rounsevell MDA (2011) A need for planned adaptation to climate change in the wine industry. Environ Res Lett 6(3):031001. https://doi.org/10.1088/1748-9326/6/3/031001

Molitor D, Caffarra A, Sinigoj P, Pertot I, Hoffmann L, Junk J (2014) Late frost damage risk for viticulture under future climate conditions: a case study for the Luxembourgish winegrowing region. Aust $\mathrm{J}$ Grape Wine Res 20(1):160-168. https://doi.org/10.1111/ajgw. 12059

Park SE, Marshall NA, Jakku E, Dowd AM, Howden SM, Mendham E, Fleming A (2012) Informing adaptation responses to climate change through theories of transformation. Glob Environ Chang 22:115126. https://doi.org/10.1016/j.gloenvcha.2011.10.003

Pfister C (1988) Variations in the spring-summer climate of central Europe from the high middle ages to 1850. In Long and short term variability of climate (pp. 57-82). Springer, Berlin, Heidelberg. doi: https://doi.org/10.1007/BFb0046590

Ramírez-Villegas J, Lau C, Köhler A-K, Signer J, Jarvis A, Arnell N, Osborne T, Hooker J (2011) Climate analogues: finding tomorrow's agriculture today. Working paper 12. Climate change agriculture and food security program, Copenhagen, Denmark http://hdl.handle.net/ 10568/16420 [accessed 22/04/14]

Ramos MC, Jones GV, Yuste J (2015) Spatial and temporal variability of cv. Tempranillo phenology and grape quality within the Ribera del Duero DO (Spain) and relationships with climate. Int J Biometeorol 59(12):1849-1860. https://doi.org/10.1007/s00484-015-0992-z

Schultze SR, Sabbatini P, Luo L (2016a) Effects of a warming trend on cool climate viticulture in Michigan, USA. SpringerPlus 5(1):1-15. https://doi.org/10.1186/s40064-016-2777-1

Schultze SR, Sabbatini P, Luo L (2016b) Interannual effects of early season growing degree day accumulation and frost in the cool climate viticulture of Michigan. Ann Am Assoc Geogr 106(5):975989. https://doi.org/10.1080/24694452.2016.1171129

Smart R (2003) Portuguese homoclimes in Australia. Aust N Z Wine Ind J 18(1):48-50

Tóth JP, Végvári Z (2016) Future of winegrape growing regions in Europe. Aust J Grape Wine Res 22(1):64-72. https://doi.org/10. 1111/ajgw.12168

Van Leeuwen C, Friant P, Chone X, Tregoat O, Koundouras S, Dubourdieu D (2004) Influence of climate, soil, and cultivar on terroir. Am J Enol Vitic 55(3):207-217

Webb LB, Whetton PH, Barlow EWR (2007) Modelled impact of future climate change on the phenology of wine grapes in Australia. Aust J Grape Wine Res 13:165-175. https://doi.org/10.1111/j.1755-0238. 2007.tb00247.x

Webb LB, Whetton PH, Barlow EWR (2008) Climate change and winegrape quality in Australia. Clim Res 36:99-111. https://doi. org/10.3354/cr00740

Webb LB, Whetton PH, Barlow EWR (2011) Observed trends in winegrape maturity in Australia. Glob Chang Biol 17:2707-2719. https://doi.org/10.1111/j.1365-2486.2011.02434.x

Webb L, Watterson I, Bhend J, Whetton P, Barlow E (2013) Global climate analogues for wine producing regions in future periods: projections of temperature and precipitation. Aust $\mathrm{J}$ Grape Wine Res 19:331-341. https://doi.org/10.1111/ajgw.12045

Webb L, Whetton P, Bhend J, Darbyshire R, Briggs P, Barlow E (2012) Earlier winegrape ripening driven by climatic warming and drying and management practices. Nat Clim Chang 2:259-264. https://doi. org/10.1038/nclimate1417

Webb L, Whiting J, Watt A, Hill T, Wigg F, Dunn G, Needs S, Barlow E (2010) Managing grapevines through severe heat: a survey of growers after the 2009 summer heatwave in south-eastern Australia. J Wine Res 21:147-165. https://doi.org/10.1080/ 09571264.2010 .530106

White MA, Diffenbaugh NS, Jones GV, Pal JS, Giorgi F (2006) Extreme heat reduces and shifts United States premium wine production in the 21st century. Proc Natl Acad Sci 103:11217-11222. https://doi. org/10.1073/pnas.0603230103 